University of Nebraska - Lincoln

DigitalCommons@University of Nebraska - Lincoln

\title{
Recasting Dilemma Zone Design as a Marginal Cost-Benefit Problem
}

\author{
Anuj Sharma \\ University of Nebraska - Lincoln, anujs@iastate.edu \\ Darcy M. Bullock \\ Purdue University \\ Srinivas Peeta \\ Purdue University
}

Follow this and additional works at: https://digitalcommons.unl.edu/civilengfacpub

Part of the Civil Engineering Commons

Sharma, Anuj; Bullock, Darcy M.; and Peeta, Srinivas, "Recasting Dilemma Zone Design as a Marginal Cost-Benefit Problem" (2007). Civil Engineering Faculty Publications. 15.

https://digitalcommons.unl.edu/civilengfacpub/15

This Article is brought to you for free and open access by the Civil Engineering at DigitalCommons@University of Nebraska - Lincoln. It has been accepted for inclusion in Civil Engineering Faculty Publications by an authorized administrator of DigitalCommons@University of Nebraska - Lincoln. 


\title{
Published in No. 2035 of Transportation Research Record: Journal of the Transportation Research Board \\ of the National Academies, Washington, D.C. (2007): 88-96. 00110.3141/2035-10. \\ Copyright 2007, the National Academies. Used by permission.
}

\section{Recasting Dilemma Zone Design as a Marginal Cost-Benefit Problem}

\author{
Anuj Sharma ${ }^{1}$, Darcy M. Bullock ${ }^{2}$ and Srinivas Peeta ${ }^{2}$ \\ ${ }^{1}$ School of Civil Engineering, University of Nebraska, Lincoln, NE; corresponding author: asharma3@unl.edu \\ ${ }^{2}$ School of Civil Engineering, Purdue University, West Lafayette, IN
}

One control objective at high-speed isolated intersections is to provide safe phase transition by minimizing the occurrence of high-speed vehicles in the dilemma zone before the phase is terminated. An upper limit for extending the green (maximum green time) is used to avoid an indefinite extension of the mainstreet green. Currently, the maximum green times are chosen by using engineering judgment. This approach does not explicitly consider the trade-offs between safety and delay and hence often results in both unsafe and inefficient performance at the intersection under medium to heavy traffic volumes. The dilemma problem is recast as one of minimizing the number of vehicles entering the upstream decision conflict zone (DCZ). An economic evaluation approach is proposed to maximize both safety and efficiency at the intersection by considering the problem in terms of marginal costs and benefits.Traffic conflicts are used to estimate potential safety benefits, and the induced delay cost is used to estimate the cost accrued on side-street traffic that is associated with extending a competing phase. This approach allows the implementation of logic that minimizes DCZ exposure instead of the current approach of absolute protection until the maximum green time is reached, at which time no consideration is given to dilemma zone exposure when the phase is terminated. This approach handles efficiently and safely the periods of moderate demand volumes when current dilemma zone protection frequently encounters maximum green time exposure.

The National Safety Council (1) reported motor vehicle crashes as the leading cause of unintentional injury deaths in the United States for 2003. A death is caused by a motor vehicle crash every 12 minutes and a disabling injury occurs every 13 seconds. The cost of motor vehicle collisions in 2005 through April totaled nearly $\$ 70.8$ billion (2). Intersection crashes constitute $30 \%$ of all vehicle crashes (3); they account for an average of 9,000 fatalities and 1.5 million injuries annually. Red light running (RLR) is a major cause of fatal and injury-related crashes. Also, motorists are more likely to be injured in such crashes. A survey conducted by the U.S. Department of Transportation and the American Trauma Society indicates that $63 \%$ of Americans witness an RLR incident more than once a week and one in three Americans knows someone who has been injured or killed because of a red light violation.

Green extension systems are deployed at rural high-speed signalized intersections to reduce the number of red light violations and rear-end crashes. A primary objective of these systems is to minimize the occurrence of high-speed vehicles in the dilemma zone. The green phase of the high-speed approach is typically extended until there is no vehicle in the di- lemma zone. An upper threshold, the maximum green time, is provided for this operation to avoid excessive delays to the cross-street traffic. Engineering judgment is used to determine the value of the maximum green time.This approach is an allor-nothing approach. High-speed. vehicles are provided complete protection against dilemma zone incursions before the maximum green is reached. However, if the maximum green is reached, the protection is completely withdrawn. Consequently, there exist no intermediate levels of protection; either the signal logic provides $100 \%$ protection for the dilemma zone in the case of gap-out or the protection drops to zero in the case of max-out.

A new approach is proposed that explicitly considers the marginal safety benefits and delay costs to maximize the safety and efficiency of a signalized intersection.

\section{BACKGROUND}

Typically, the total number of vehicles in the dilemma zone is used as a surrogate measure for safety at rural high-speed intersections.

Defining the Dilemma Zone

Researchers typically characterize the decision dilemma zone as that approach area within which the probability of deciding to stop on the display of yellow is within the range of $10 \%$ to $90 \%$ (4-7). At the onset of yellow, a high-speed vehicle is confronted by the decision to stop or to go. The dilemma zone is typically defined as the region in which more than $10 \%$ but less than $90 \%$ of drivers decide to stop. This zone is considered to have a higher risk for rear-end collisions and red light violations because the driver is not sure whether to proceed through the intersection or to attempt to stop. Figure 1 shows a hypothetical case in which two vehicles are caught in the dilemma zone on the onset of yellow. If Vehicle 2 decides to stop and Vehicle 3 decides to proceed through the intersection, there will be an increased probability of a rear-end crash. Similarly, if a vehicle is caught in the dilemma zone and incorrectly decides to cross the intersection, it can cause a red light violation.

There have been several attempts to define the dilemma zone boundaries relative to the intersection stop bar $(4,6-12)$. Table 1 gives some of the common dilemma zone boundaries reported by researchers. There are slight variations in the defined boundaries because of the variations in the definition of dilemma zone, type of drivers, and geometric and environmental characteristics of the investigation sites.

Time can also be used instead of distance as a measure for decision dilemma zone boundaries. On the basis of limits given by Zegeer and Deen (8) and by Parsonson (5), it can be calcu- 


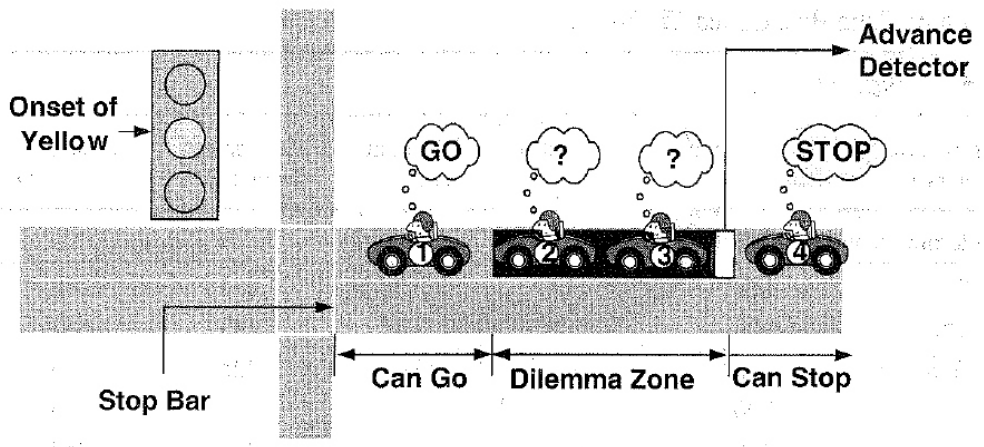

(a)

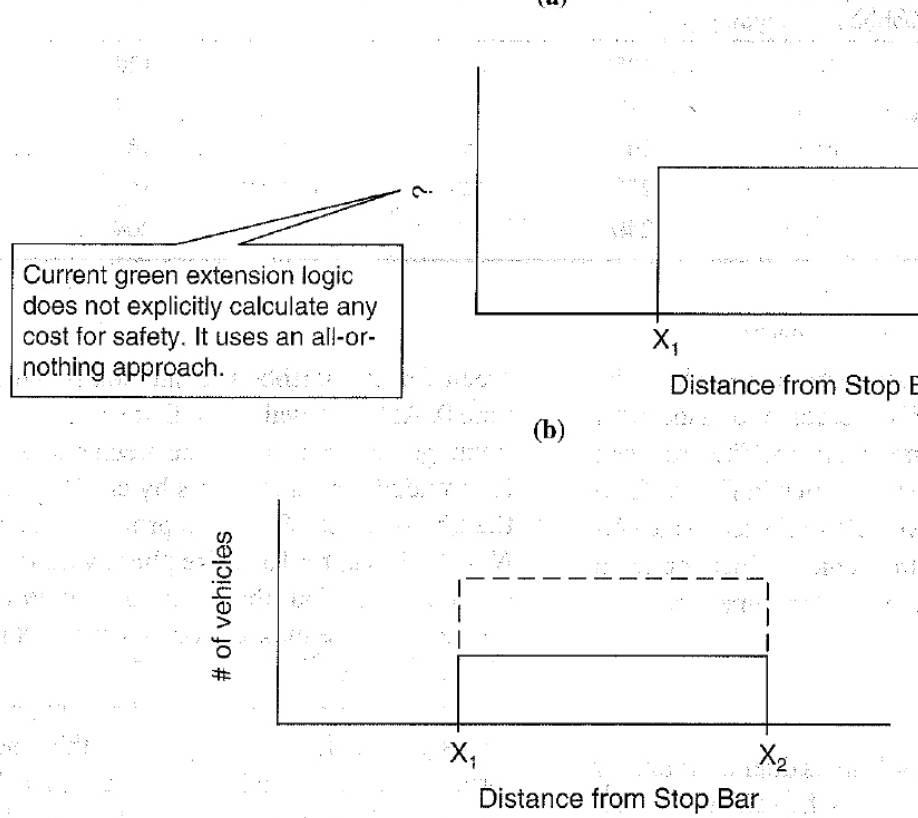

(c)

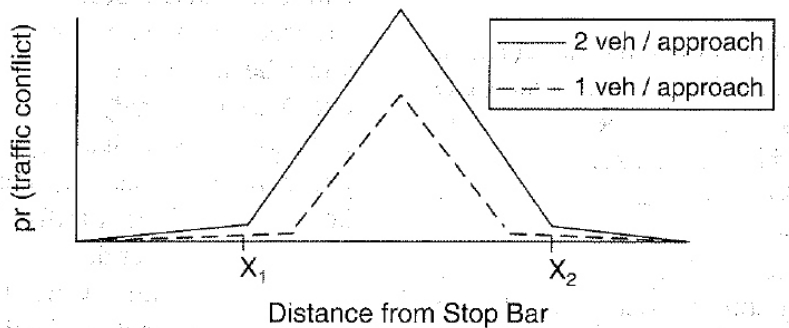

(d)

FIGURE 1 Dilemma zone and safety cost evaluation: (a) dilemma zone, $(b)$ safety cost evaluation in current green extension systems, [c] safety cost evaluation in advance green termination systems, and (d) proposed evaluation of safety cost.

lated that around $90 \%$ of traffic stops if the passage time to the stop bar is 4.5 to 5 seconds or greater and only $10 \%$ of traffic stops if the passage time to the stop bar is less than 2 to $2.5 \mathrm{sec}-$ onds Bonneson et al. (12) indicate that the beginning of the dilemma zone is 5.0 to 6.0 seconds upstream and the end is about 3.0 seconds upstream.

In Figures $1 \mathrm{~b}$ through $\mathrm{d}$ the current approaches are contrasted with the proposed approach for the safe passage of vehicles on high-speed approaches. Widely used green extension systems are all-or-nothing approaches. All the vehicles on the high-speed approaches are cleared until the maximum green time is reached. At the end of the maximum green time none of the vehicles on the high-speed approach is provided any protection. As shown in Figure lb these systems do not have any metric to measure the cost of safety. The green termination systems use the number of vehicles in the dilemma zone as a surrogate measure for the cost of safety. The number of vehicles is a rank-ordered metric (Figure 1c) in which the cost of one vehi- 
TABLE 1 Dilemma Zone Boundaries $(5,7-12)$

\begin{tabular}{|c|c|c|c|c|c|c|c|}
\hline \multirow[b]{2}{*}{$\begin{array}{l}\text { Speed } \\
(\mathrm{mph})\end{array}$} & \multicolumn{7}{|c|}{ Distance of Stop Line, $\mathrm{ft}$} \\
\hline & $\begin{array}{l}\text { Olson and } \\
\text { Rothery }(9)\end{array}$ & $\begin{array}{l}\text { Webster and } \\
\text { Ellson }(10)\end{array}$ & $\begin{array}{l}\text { Parsonson } \\
\text { (5) }\end{array}$ & $\begin{array}{l}\text { Herman } \\
\text { et al. }(7)\end{array}$ & $\begin{array}{l}\text { Zegeer and } \\
\text { Deen }(8)\end{array}$ & $\begin{array}{l}\text { Chang } \\
\text { et al. (11) }\end{array}$ & $\begin{array}{l}\text { Bonneson } \\
\text { et al. (12) }\end{array}$ \\
\hline \multicolumn{8}{|c|}{ Beginning of dilemma zone (probability of stopping $=0.9$ ) } \\
\hline 35 & $212^{a}$ & $170^{a}$ & $212^{a}$ & $218^{a}$ & 254 & 288 & 245 \\
\hline 40 & 255 & 205 & 250 & 260 & 283 & 307 & 293 \\
\hline 45 & $315^{a}$ & $252^{a}$ & 300 & $315^{a}$ & 325 & 326 & 343 \\
\hline 50 & 375 & 300 & 350 & 370 & 350 & 345 & 396 \\
\hline 55 & - & $370^{\prime \prime}$ & $400^{a}$ & - & 384 & 364 & 452 \\
\hline \multicolumn{8}{|c|}{ End of dilemma zone (probability of stopping $=0.1$ ) } \\
\hline 35 & $103^{a}$ & $103^{a}$ & $105^{a}$ & $100^{4}$ & 103 & 128 & 145 \\
\hline 40 & 110 & 125 & 110 & 110 & 121 & 147 & 178 \\
\hline 45 & $165^{a}$ & $155^{a}$ & 165 & $165^{a}$ & 152 & 166 & 213 \\
\hline 50 & 220 & 185 & 220 & 220 & 170 & 185 & 252 \\
\hline 55 & $\therefore$ & $230^{a}$ & $240^{a}$ & - & 232 & 204 & 294 \\
\hline
\end{tabular}

cle in the dilemma zone is less than the cost of two vehicles in the dilemma zone, but the cost is independent of the position of the vehicle in the dilemma zone. Also, there has been a lack of research to associate a monetary cost of safety for a dilemma zone incursion. The proposed approach proposes touse a hazard function as shown in Figure 1d to calculate the monetary cost of safety for a vehicle subjected to the yellow indication. The function is based on the vehicle's location from the intersection and presence of other vehicles in the same lane.

\section{Vehicle Detection Systems}

A vehicle detection system monitors a vehicle in its dilemma zone by using detectors, with the objective of clearing all the vehicles in their dilemma zone before the change to the next signal phase. Two kinds of vehicle detection systems exist: green extension systems and green termination systems.

Green extension systems are the most commonly implemented control algorithm at high-speed intersections in the United States. The objective of this control mechanism is to improve the safety at the intersection by allowing the driver in the dilemma zone to proceed safely through before the phase transition. The operation of simultaneous gap-out logic for green extension is shown in Figure 2. A hypothetical traffic signal is shown in Figure 2a. This intersection has a high-speed through movement running north to south. The advance detectors present on the high-speed arterial mark the beginning of the dilemma zone. Both the advance detectors, on the northbound and southbound arterial, are connected in series. The northbound and southbound through phases are simultaneously extended for a prespecified green extension time on detection of a vehicle. The green extension time is sufficient to carry the detected vehicle through the dilemma zone. So the green through phase for northbound and southbound movements is terminated when there is no vehicle present in the dilemma zone on either ofthe two approaches. Such a termination of the phase is called a gap-out. The through phase can also be terminated if the traffic controller is unable to find a gap before the maximum green time has expired. Such a termination of the green phase is called a max-out.

Figure $2 \mathrm{~b}$ shows the actuation time diagram for the hypothetical traffic flow shown in Figure 2a. A green extension time of 3 seconds and maximum green time of 18 seconds are assumed.
The signal is resting in green for the northbound and southbound through movements at time 0 . At the arrival of the first vehicle on the cross street, the maximum green timer starts. The green phase for the through movement is extended for 3 seconds at $t=1$ second by car N-1 and it is again extended by the arrival of car S-1. This process is continued until the last car, N-3, arrives at $t=16$ seconds. The phase would have terminated as a gapout at $t=19$ seconds, but the maximum green time is set to be 18 seconds and hence the phase max-out Occurs at $t=18$ seconds, leaving a vehicle in the dilemma zone.

This simple example illustrates a major drawback in the simultaneous gap-out logic. If only the northbound traffic were present, the through phase would have gap-out at $t=4$ seconds, and if only the southbound traffic were present, the phase would have gap-out at $t=12$ seconds. The increase in the number of lanes decreases the probability of gap-out. This problem becomes worse when the high-speed arterial carries medium to heavy traffic volumes. The safety benefits are negated when the high-speed through phase is arbitrarily terminated by max-out. A detailed analysis of this problem was made by Sharma et al. (13), who showed that the implementation of the simultaneous gap-out logic led to max-outs ranging from $3.5 \%$ to $40 \%$ of cycles per hour during the peak traffic flow periods and around 200 dilemma zone incursions per day.

Although some advanced green extension systems, such as the Texas Transportation Institute truck priority system (14) and LHORVA (15) exist, none to date explicitly consider the marginal trade-offs between safety and delay.

Unlike the green extension systems just described, green termination systems use a look-ahead window to determine the best time to end a phase. Examples of green termination systems are the intelligent detection-control system from Texas (16) and SOS from Sweden (17). These systems try to identify an appropriate time to end the green phase by predicting the value of a performance function for the.near future. This performance function is based on the number of vehicles present in the dilemma zone and the opposing queue. The cost of safety is calculated by using the number of vehicles in the dilemma zone. These control systems are not widely used owing to the high technology cost.

Methodologies $(18,19)$ have also been developed that dynamically vary the clearance intervals (yellow clearance and all red) 


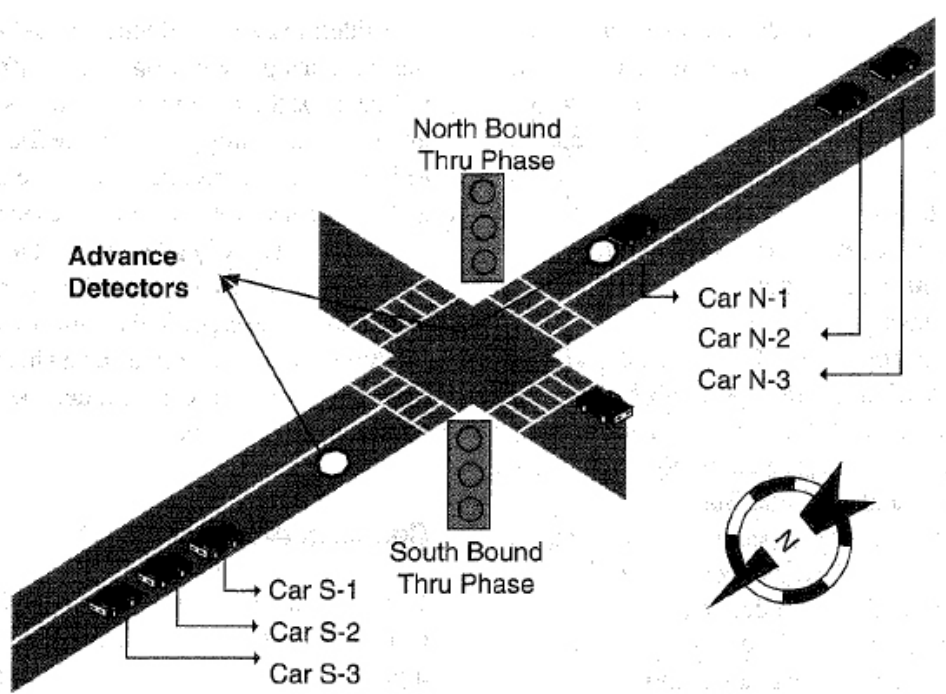

(a)

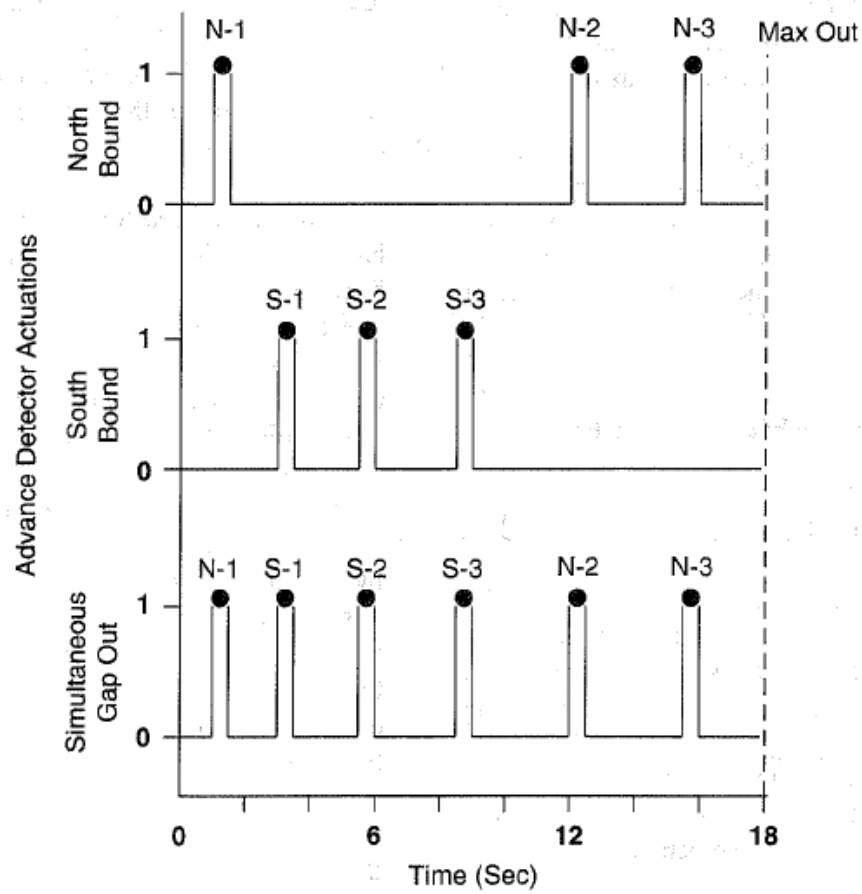

(b)

FIGURE 2 Simultaneous gap-out logic: (a) example intersection and (b) example detector inputs.

to Figure 2 Simultaneous gap-out logic: (a) example intersection and (b) example detector inputs. minimize dilemma zone incursions. However, they have not been widely implemented or tested.

\section{TRAFFIC CONFLICT AS SURROGATE MEASURE FOR SAFETY}

The traffic conflict technique (TCT) was first proposed in 1967 by Perkins and Harris (20). They defined a conflict as "the occurrence of evasive actions, such as braking or weaving, which are forced on the driver by an impending accident situation or a traffic violation." The conflicts were categorized as left-tum conflicts, weave conflicts, rear-end conflicts, and cross-traffic conflicts.

This technique gained wide publicity as a surrogate for measuring traffic safety for two main reasons. First, traffic conflicts are more frequently observed than accidents, so a large amount of information about intersection safety can be collected quickly. Cooper and Ferguson (21) reported that, on average, the ratio of rate of crashes to rate of serious conflicts lies in the range of 1:2,000, so 10 hours of observation of conflicts at a site provides information equivalent to 2 to 3 years of re- 
ported accident records. Second, it provides an opportunity for traffic engineers to proactively improve the safety of a site instead of waiting for the accident history to evolve. Because of these advantages, TCT was used by several agencies to investigate accident potential and operational deficiencies ofintersections. There were numerous research efforts to establish a direct relationship between accidents and conflicts $(22,23)$. A review in 1980 by Glauz and Migletz (24) identified 33 previous studies that (at least partly) dealt with the conflict-accident relationships (25-29).

Some concerns have been raised regarding TCT (30) since the general approach used initially was to compare the observed crashes with the observed surrogate measure. Since both the conflict and the accident are randomly distributed events, it would be highly improbable to predict the exact number of accidents at a site. Glauz et al. (31) proposed a new approach that compared the expected accident rate as predicted by conflict ratios with the expected accident rate as predicted by accident histories. This study concluded that an estimate of the expected accident rates can be computed from the data obtained from traffic conflicts with nearly the same accuracy as those predicted by the accident history.

Some recent studies $(21,32)$ also advocate the use of traffic conflicts as a surrogate measure for traffic safety in microsimulation packages. Gettman and Head (33) provided a detailed use-case analysis for traffic conflict as a surrogate measure for safety in a simulation package.

In summary, the literature review indicates a long history of development for TCT, which suggests that it can be used effectively as a surrogate measure of traffic safety at intersections. Next, the proposed methodology is described for use of traffic conflicts to estimate the safety benefits associated with decision conflict zane (DCZ) protection at high-speed rural intersections.

\section{PROPOSED MARGINAL COST-BENEFIT MODEL}

The high-speed intersection can be operated in an economically efficient manner by using the following control logic:

1. A minimum green time is allotted to each phase for avoiding the short-green dilemma. Parsonson (34) suggested this term forthe scenario in which the green is too short to violate the driver's expectancy. Minimum green time may also be governed by pedestrian safety issues.

2. Phases remain green beyond their minimum green as long as they are still discharging at or near saturation (unless the maximum green time is reached). This operation is implemented by using stop bar detectors (35).

3. The high-speed through phase is extended beyond the end of the saturation discharge rate until the cost experienced by the opposing movements exceeds the estimated safety benefits associated with extending the phase. This operation allows the problem to be cast as a marginal cost-benefit problem.

To implement this logic, the benefits associated with reducing dilemma zone incursions as well as the costs experienced by opposing movements must be estimated.

\section{Application of DCZ Concept}

Currently, safety benefits are not explicitly calculated in any of the green extension systems. Green termination systems calculate the safety benefits by using the number of vehicles in the dilemma zone.

A dilemma zone is defined by using the probability of stop- ping as the measuring scale. Logically, traffic conflict seems to be a better indicator of the number of accidents at a specific site than the probability of stopping. Traffic conflicts have been found in the past to have a high correlation with the number of accidents occurring at the intersection. So in this research a DCZ is used instead of a dilemma zone. A DCZ is defined as the region in which the driver must make a decision regarding conflicting options of stopping or proceeding through. This region can be represented by a hazard function (Figure 3), where during heavier periods of traffic, one could seek to minimize the area under these functions instead of trying to eliminate all conflicts.

\section{Conflicts Affecting Safety}

Green extension systems can be deployed to mitigate the occurrence of vehicles in the DCZ. The boundaries of the DCZ can be defined for a particular intersection by conducting field surveys. Here, the only concern is with the traffic conflicts that can be affected by the onset of yellow (or extension of green time). Zegeer (6) identified six conflicts that can be affected by green extension systems:

- Run red light. A red light violation can be defined as occurring when most of the vehicle is behind the stop bar at the onset of red.

- Abrupt stop. An abrupt stop occurs when a vehicle makes an unusually quick deceleration, particularly within $100 \mathrm{ft}$ of the stop bar. This conflict can be recognized by a noticeable dipping of the front end and is an obvious last-second decision.

- Swerve to avoid collision. This conflict is an erratic maneuver in which drivers swerve out of their lane to avoid hitting the vehicle that had stopped for the light in front of them.

- Vehicle skid. This conflict is a more severe case of the abrupt stop. The sound of a vehicle skidding can be heard when wheels of the vehicle lock up to stop during the yellow phase.

- Acceleration through yellow. This conflict can be recognized by actually seeing or hearing a sudden acceleration.

- Brakes applied before passing through. This conflict indicates the indecision of the driver before finally deciding to pass through the red phase. It should be carefully considered since in some cases drivers brake to slow down their vehicles because of downgrades or heavy traffic.

In case an observed conflict can be classified in more than one of the categories, it must be classified under the most severe group.

\section{Modeling Hazard Function for DCZ}

After the intersection under investigation has been surveyed, the probability of occurrence of a traffic conflict (TC) given the location of vehicle at the onset of yellow $[\operatorname{Pr}(\mathrm{TC} \mid \mathrm{Dist})]$ needs to be computed. This probability is defined as the total number of vehicles exposed to conflict divided by the total numberof vehicles facing the amber light at a given distance from the stop bar. The probability distribution of conflicts at a given distance from the stop bar will then be used as a hazard function to calculate the benefits of safety. Figure 3 shows a hypothetical hazard function for a given site and a higher probability for two vehicles involved in the traffic conflict on the same approach as compared with only a single vehicle in the DCZ. This distribution is found because there are more types of conflict if more than one vehicle is present in the DCZ. For example, Swerving to avoid collision can only occur when two vehicles are in their conflict zone. 


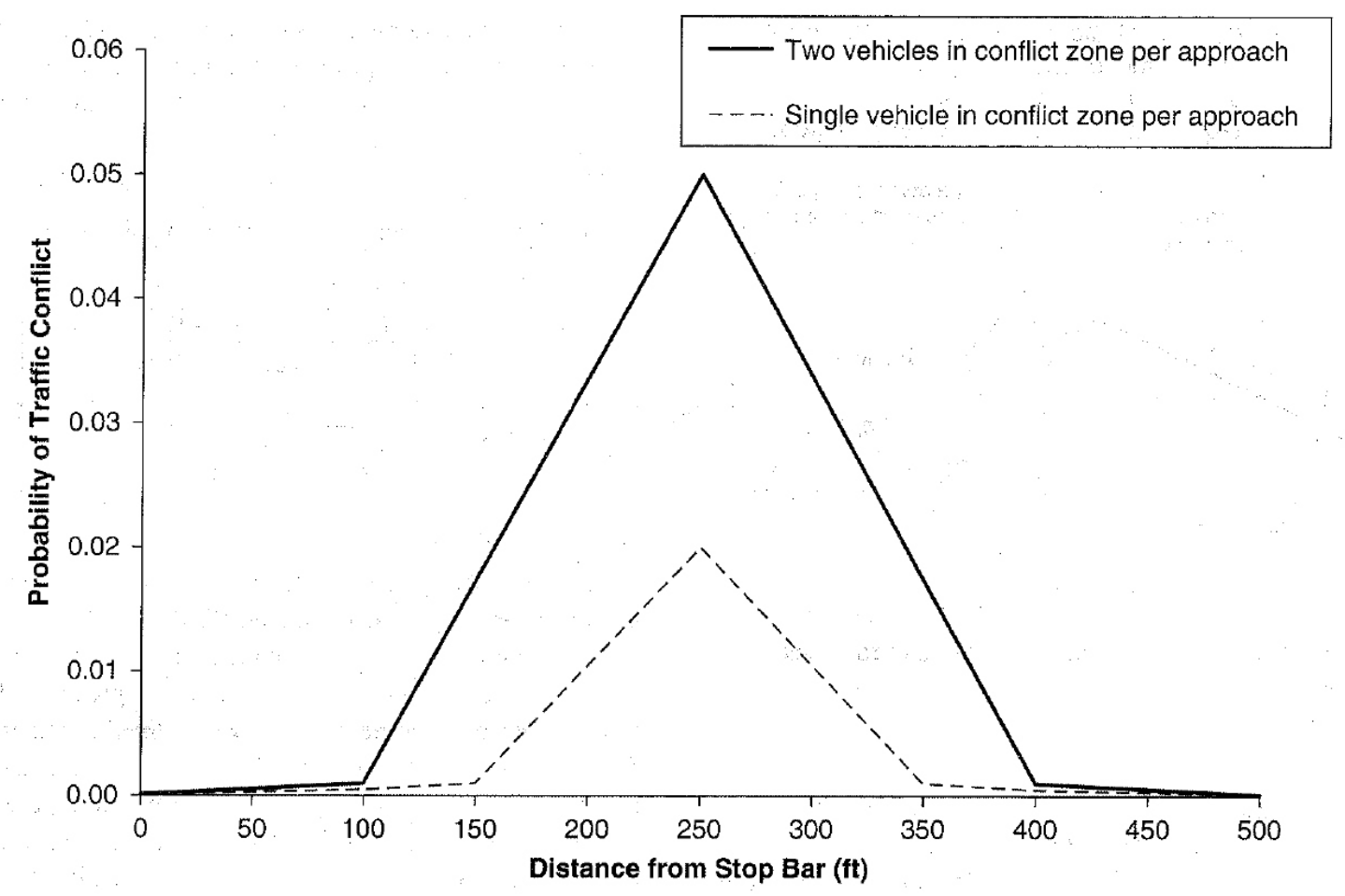

FIGURE 3 Hypothetical hazard function for intersections.

The next step after developing the hazard function is to compute the benefits of preventing a particular conflict. There can be two approaches to calculate the cost of conflicts. The first is to do a survey of a representative set of drivers to obtain information on the cost they associate with each type of conflict. The second approach is to evaluate benefits by calculating the probability of an accident given a particular type of conflict $[\operatorname{Pr}$ (Accident |Conflict)]. The comprehensive cost of each accident can then be used to calculate the benefits of preventing a traffic conflict. In this research the latter approach was used for calculating the safety benefits for preventing vehicles from being in their DCZ at the onset of yellow.

Table 2 gives an example of calculating the benefits of preventing a single traffic conflict. For simplicity, a single probability value of a traffic conflict is used instead of a hazard function. Conservatively, the highest value of the probability of conflict throughout the DCZ is assumed. Columns 1 and 2 in the upper part of Table 2 give the type of crash and the comprehensive cost associated with each, respectively, as reported by the National Safety Council (1). The weighted average cost of the accident is calculated by using the current year ratios for the type of accident. The estimated benefits of preventing the traffic conflict are obtained as the product of the average accident cost and the probability of occurrence of a crash given that a traffic conflict has occurred. For this example, the estimated benefit of preventing a single traffic conflict is $\$ 5.67$. Multiplying the probability of the occurrence of a traffic conflict and the benefit ofpreventing it gives the benefit ofpreventing a single vehicle from entering the DCZ. For this example, this cost was estimated to be $\$ 0.45$. These numbers can be different for different intersections and are used here only to illustrate the concept.
Cost of Delay with Extension of Green Phase on High-Speed Approach

The cost of clearing a vehicle through its DCZ can be calculated by using the amount of delay incurred by the queue that formed on the stopped phases. Figure 4 shows the concept of

TABLE 2 Estimation of Cost Associated with Traffic Conflict

\begin{tabular}{|c|c|c|c|}
\hline Type of Crash & $\begin{array}{l}\text { Comprehensive } \\
\text { Cost, } 2004(1)\end{array}$ & $\begin{array}{l}\text { Ratio of Each } \\
\text { Type of Crash }\end{array}$ & Ratio $*$ Cost \\
\hline Death & $\$ 3,760,000$ & 1 & $\$ 3,760,000$ \\
\hline Incapacitating injury & $\$ 188,000$ & 100 & $18,800,000$ \\
\hline $\begin{array}{l}\text { Nonincapacitating } \\
\text { evident injury }\end{array}$ & $\$ 48,200$ & 100 & $\$ 4,820,000$ \\
\hline Possible injury & $\$ 22,900$ & 100 & $\$ 2,290,000$ \\
\hline No injury & $\$ 2,100$ & 231 & $\$ 484,615$ \\
\hline \multicolumn{3}{|c|}{$\begin{array}{l}\text { Weighted average comprehensive cost per crash } \\
{[\operatorname{cost}(\$ / \text { crash })]}\end{array}$} & $\$ 56,706$ \\
\hline \multicolumn{3}{|c|}{$\begin{array}{l}\text { Probability of getting involved in a crash given } \\
\text { a traffic conflict }[\operatorname{Pr}(\text { crash } \mid \text { TC })](22)\end{array}$} & 0.0001 \\
\hline \multicolumn{3}{|c|}{$\begin{array}{l}\text { Estimated benefits of preventing a traffic conflict } \\
\quad[\text { benefits }(\$ / \mathrm{TC})=\operatorname{cost}(\$ / \text { crash }) \times \operatorname{Pr}(\text { crash } \mid \text { TC })]\end{array}$} & $\$ 5.67$ \\
\hline \multicolumn{3}{|c|}{ Probability of having a traffic conflict $[\operatorname{Pr}(\mathrm{Tc})](22)$} & 0.08 \\
\hline \multicolumn{3}{|c|}{$\begin{array}{l}\text { Benefits of preventing one vehicle from its decision conflict } \\
\text { zone }[\text { benefits }(\$ / \text { incursion })=\operatorname{Pr}(\mathrm{TC}) \times \text { benefits }(\$ / \mathrm{TC})]\end{array}$} & $\$ 0.45$ \\
\hline \multicolumn{3}{|c|}{ Benefits of preventing two vehicles in their decision conflict zone } & $\$ 0.91$ \\
\hline \multicolumn{3}{|c|}{ Benefits of preventing three vehicles in their decision conflict zone } & $\$ 1.81$ \\
\hline \multicolumn{3}{|c|}{ Benefits of preventing four vehicles in their decision conflict zone } & $\$ 3.63$ \\
\hline
\end{tabular}




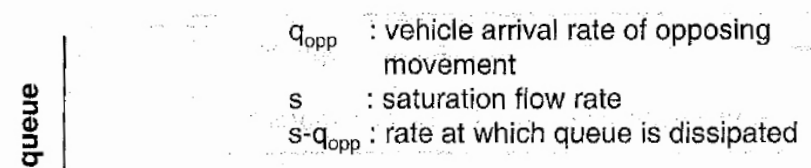

Area 2 corresponds to the extra delay for opposing traffic due to vehicle extension for high-speed through movement

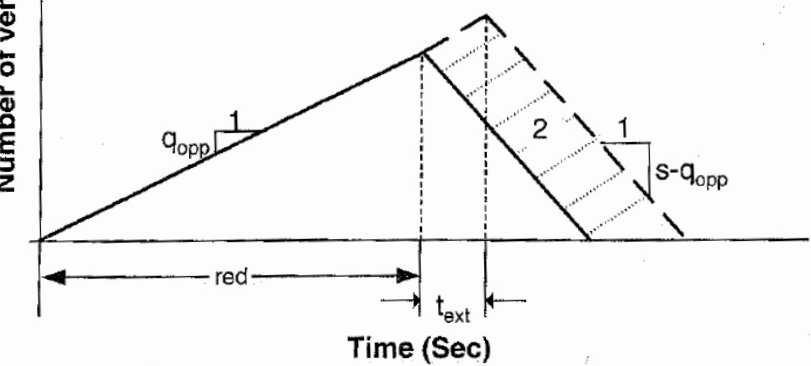

FIGURE 4 Increase in delay of standing queue due to vehicle extension.

an increase in delay for extending a through green by a single vehicle extension $\left(t_{\text {ext }}\right)$. The unshaded queue polygon in Figure 4 is the delay experienced by vehicles in the opposing movement if the green is terminated without the green extension. The extra delay is shown as the shaded area, and this extra delay accrues to the side-street traffic if the through phase is extended by a time equal to fext. The total area under the shaded region is calculated as follows:

$$
\Delta \text { delay }=\frac{q_{\mathrm{opp}}}{\left(1-\frac{q_{\mathrm{opp}}}{s_{\mathrm{opp}}}\right)} \times r \times t_{\mathrm{ext}}+\frac{q_{\mathrm{opp}}}{2 \times\left(1-\frac{q_{\mathrm{opp}}}{s_{\mathrm{opp}}}\right)} \times t_{\mathrm{ext}}^{2}
$$

where

$$
\begin{aligned}
\Delta \text { delay }= & \text { increase in total delay for extending through } \\
& \text { green by a unit vehicle extension (veh-s) } \\
q_{\text {opp }}= & \text { total volume in opposing direction (veh/s), } \\
s_{\mathrm{opp}}= & \text { saturation flow rate for opposing movements } \\
(\mathrm{veh} / \mathrm{s}), & \\
r= & \text { red time elapsed for opposing movements (s), and } \\
t_{\mathrm{ext}}= & \text { vehicle extension time. }
\end{aligned}
$$

The increase in the total system delay is multiplied by the cost of delay $[\$ /(v e h-s)]$ to obtain the cost of extending the highspeed through phase by a unit vehicle extension.

\section{Break-Even Concept}

After the safety benefits and delay costs have been calculated, the break-even points can be determined. A break-even point is the point in time when the cost of allowing $n$ vehicles on $m$ approaches from their DCZ equals the increase in the system delay cost associated with clearing them through. The constraint to be met at the break-even point is

$\Delta$ delay $\times \operatorname{cost}(\$ /$ veh-s $)=\operatorname{Pr}\left(\mathrm{TC}_{n, m}\right) \times$ benefits $\left(\$ / \mathrm{TC}_{n, m}\right)$

where

$\Delta$ delay $=$ increase in system delay if high-speed through phase is extended,

$$
\begin{aligned}
\operatorname{cost}(\$ / \text { veh-s })= & \text { cost of delay per unit (veh-s), } \\
\operatorname{Pr}\left(\mathrm{TC}_{n, m}\right)= & \text { probability that } n \text { vehicles on } m \text { ap- } \\
& \text { proaches have traffic conflicts if green } \\
& \text { is not extended, and } \\
\text { benefits }\left(\$ / \mathrm{TC}_{n, m}\right)= & \text { benefits of preventing traffic conflict. }
\end{aligned}
$$

From Equations 1 and 2, the break-even point is obtained as follows:

$$
r_{n, m}=\frac{\left(1-\frac{q_{\mathrm{opp}}}{s_{\mathrm{opp}}}\right)}{q_{\mathrm{opp}} \times t_{\mathrm{ext}}} \times\left(\begin{array}{l}
\frac{\operatorname{Pr}\left(\mathrm{TC}_{n, m}\right) \times \text { benefits }\left(\$ / \mathrm{TC}_{n, m}\right)}{\operatorname{cost}(\$ / \text { veh-s })} \\
-\frac{q_{\mathrm{opp}}}{2 \times\left(1-\frac{q_{\mathrm{opp}}}{s_{\mathrm{opp}}}\right)} \times t_{\mathrm{oxt}}^{2}
\end{array}\right)
$$

The value of $r_{n, m}$ then represents the break-even point for subjecting $n$ vehicles on $m$ approaches to their DCZ.

Figure 5 graphs the concept of the economic evaluation of costs and benefits associated with the extension of the green for the high-speed through phase. The time from the start of the through green (seconds) for the high-speed movement is plotted versus the associated value (\$). The thick solid lines represent the estimated increase in the cost of system delay and the thinner solid lines represent the safety benefits. For example, for the specific case of an opposing volume of 4,000 vph, it can be seen thatthe marginal delay cost increases linearly with time. This marginal delay cost function intersects the safety benefits function for preventing one vehicle from its DCZ on a single approach at time $t_{1,4000}$. Hence, before this point the safety benefits of preventing a single vehicle from its DCZ are higher than the increase in system delay cost. Therefore, up to $t_{1,4000}$, all vehicles are prevented from being subjected to their DCZ. Once the through green extends past $t_{1,4000}$, the safety benefits for saving a single vehicle become lower than the associated marginal delay cost. Beyond that point, if only one vehicle is being subjected to its DCZ, the green phase should be terminated (gap-out).

Similarly, the marginal delay function intersects the safety benefits line for subjecting two vehicles on different approaches to their DCZs at time $t_{2,4000}$. Therefore, beyond this point the green phase should be terminated even if two vehicles are being Subjected to their DCZ, Figure 5 also shows the marginal delay cost function for the opposing volume of $3,500 \mathrm{vph}$. The delay cost function at a lower volume increases at a lower rate. Therefore, the break-even points $t_{1,3500}, t_{2,3500}, t_{3,3500}$ are shifted toward the right of the break -even points for an opposing volume of 4,000 vph, Not surprisingly, for a lower opposing volume, the high-speed through green should be extended for a longer duration before vehicles are subjected to their DCZ.

For an intersection with a set of advance detectors, the proposed logic can be implemented. Depending on the volume of the opposing movement, break-even points can be computed for-the specific site. If the total volume of the opposing movements is $4,000 \mathrm{vph}$ during a given time of day, full (100\%) protection will be provided until $t_{1,4000}$ is reached. Beyond this point, the controller will allow the phase to gap out even if there is one vehicle in its DCZ. Similarly, after $t_{2,4000}$ the green phase can be terminated if there exist two or fewer vehicles on different approaches in the DCZ. So the safety protection follows a step descent from $100 \%$ protection to $0 \%$ with paints of reduction lying at every break-even point.

A more refined logic can be implemented if one can measure the queue lengths at the cross streets and the speeds and positions of the high-speed through vehicles. Precise estimates 


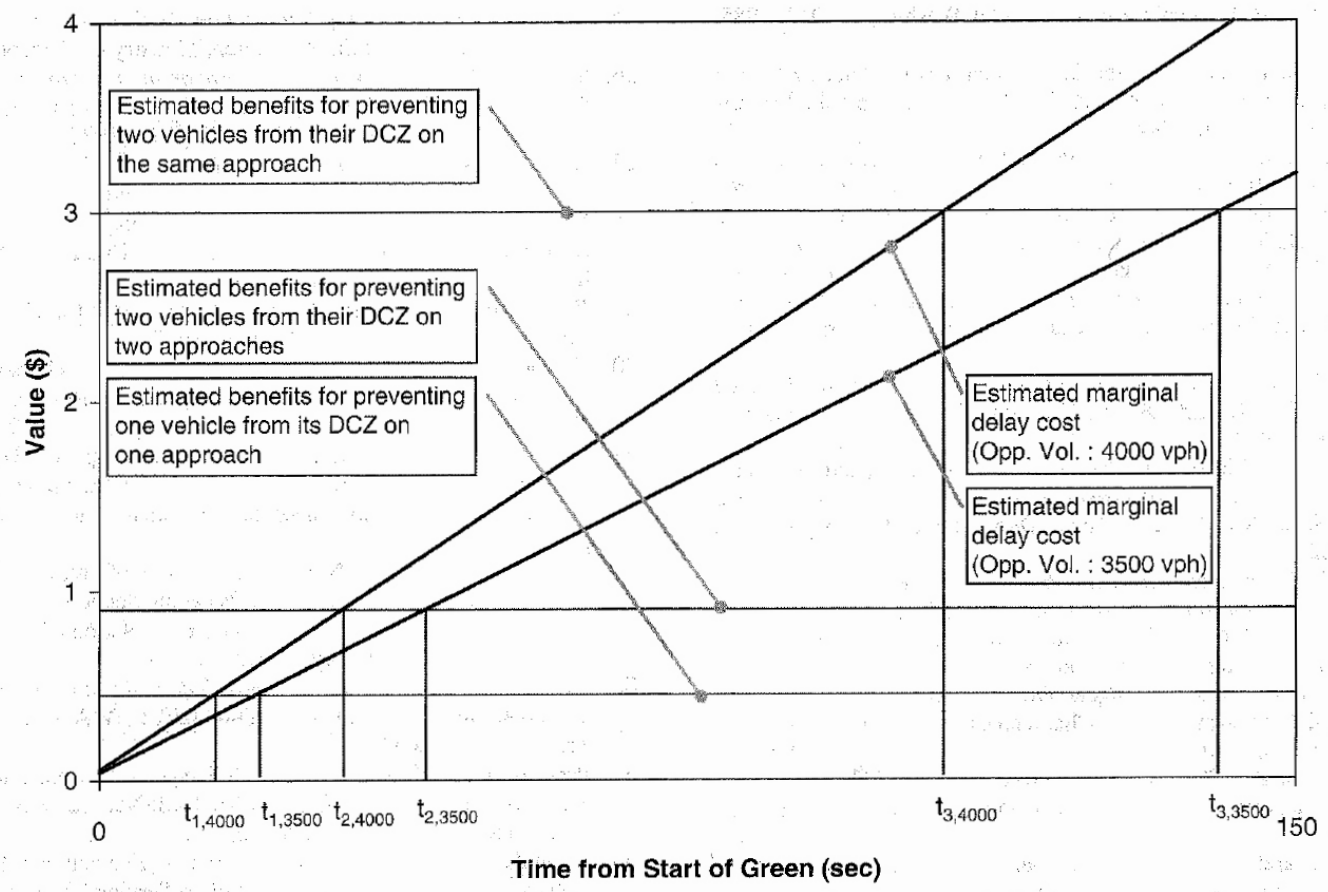

FIGURE 5 Marginal cost and benefit curves for dilemma zone incursions.

of increment delays for the opposing traffic can be made for extending the main-street green phases by using the current queue profile. If the position of the vehicles can be exactly determined, more precise estimates ofsafety cost can be obtained. The proposed technique can be implemented with theprevalent detection system, but the performance of the technique can be further enhanced by using technologically advanced detection systems.

As the through volume increases, the probability of finding a gap greater than the vehicle extension time decreases, thereby decreasing the probability of realizing $100 \%$ safety benefits for all the high-speed approaches. The important point is that as traffic volumes increase, the probability of finding concurrent gaps on all through lanes (in both directions) of a high-speed approach becomes quite small.

\section{DISCUSSION OF RESULTS}

The current green extension logic for dilemma zone protection uses an arbitrary all-or-nothing approach for signal operations. Full (1 00\%) safety benefits are provided to high-speed vehicles when green phases gap out before the maximum green time is reached. In cases where the maximum green time value forces a phase termination, dilemma zone protection is completely ignored. The proposed approach uses a hazard function so that during periods of moderate and heavy traffic, the controller can seek to minimize DCZ exposure. This explicit reduction in dilemma zone boundaties is hypothesized to provide safer operation because some level of DCZ can be provided during petiods when traditional all-or-nothing dilemma zone operation is overtidden by maximum green time constraints.

This DCZ methodology is formalized in an economic evaluation framework. The methodology uses TCT for assessing safety benefits and estimates the marginal delay costs by using the queue polygon technique. The trade-offs between safety and efficiency are evaluated for efficient and safe operation at high-speed intersections. A further benefit of using an economic perspective is the transparency available to field practitionersin trading off the costs and benefits.

\section{ACKNOWLEDGMENT}

This work was supported by the National Science Foundation.

\section{REFERENCES}

1. Injury Facts, 2004-2005 ed. National Safety Council, 2004.

2. Kearn, K. T. April Trame Deaths Up 2 Percent. Traffic Safety, Vol 5, No. 8, Aug. 2005.

3. Intersection Decision Support Fact Sheet. ITS Institute, University of Minnesota, http://www.its.umn.edu/Research/FeaturedStudies/ ids.

4. May, A. D. Clearance Interval at Flashing Systems. In: Highway Research Record 221, HRB, National Research Council, Washington, D.C., 1968.

5. Parsonson, P. S. (chairman), ITE Technical Committee 18, Small-Area Detection at Intersection Approaches, Traffic Engineering, Feb. 1974, pp. 8-17.

6. Zegeer, C. V. Effectiveness of Green-Extension Systems at HighSpeed Intersections. Research Report 472. Bureau of Highways, Kentucky Department of Transportation, Lexington, 1977.

7. Herman, R., P. L. Olson and R. W. Rothery. Problem of the Amber Signal Light. Traffic Engineering and Control, Vol. 5, 1963. pp. 298304.

8. Zegeer, C. V. and R. C. Deen. Green Extension Systems at HighSpeed Intersections, ITE Journal, Nov. 1978, pp. 19-24.

9. Olson, P. O. and R. Rothery, Driver Response to Amber Phase of Traffic Signals. Bulletin 330, HRB, National Research Council, Washington, D.C., 1962, pp. 40-51.

10. Webster, F. V. and P. B. Elison. Traffic Signals for High-Speed Roads. RRL Technical Paper 74. U.K. Transport and Road Research Laboratory, Crowthorne, Berkshire, England, 1965.

11. Chang, M.-S., C. J. Messer and A. J. Santiago, Timing Traffic Signal Change Intervals Based on Driver Behavior. Transportation Research 
Record 1027, 1985, pp. 20-30

12. Bonneson, J. A., P. T. McCoy and B. A. Moen. Traffic Detector Design and Evaluation Guidelines. Report TRP-02-31-93. Nebraska Department of Roads, Lincoln, 1994.

13. Sharma, A., D. M. Bullock and S. Peeta. Limitations of Simultaneous Gap-Out Logic. Transportation Research Record, No. 1978, 2006, pp. 42-48.

14. Middleton, D., D. Jasek, H. Charara and D. Moris. Evaluation of Innovative Methods to Reduce Stops to Trucks at Isolated Signalized Intersections. Report TX-97/2972-S. Texas Department of Transportation, Austin, 1997.

15. Kronborg, P. MOVA and LHOVRA Traffic Signal Control for Isolated Intersections. TFK Report 1992: 4E. Transport Research Institute, Stockholm, Sweden, 1992.

16. Bonneson, J., D. Middleton, K. Zimmerman, H. Charara and M. Abbas. Intelligent Detection-Control System for Rural Signalized Intersections. Report FHWA/TX-03/4022-2. Texas Department of Transportation, Austin, 2002.

17. Kronborg, P., F. Davidsson and J. Edholm. SOS-Self-Optimising Signal Control Development and Field Trials of the SOS Algorithm for Self-Optimising Signal Control at Isolated Intersections. TFK Report 1997: 2E. Transport Research Institute, Stockholm, Sweden, 1997.

18. Saito, T., N. Ooyarna and K. Sigeta. Dilemma and Option Zones: The Problem and Countermeasures-Characteristics of Zones, and a New Strategy of Signal Control for Minimizing Zones. Proc., Third International Conference on Road Traffic Control, 1990, pp. 137141.

19. Red Light Hold. Optisoft-ITS.com. http://www.optisoft-its.com/ products.cfm? PageID=39.

20. Perkins, S. R. and J. I. Harris. Traffic Conflict Characteristics - Accident Potential at Intersections. Highway Research Record 225, HRB, 1968, pp. 35-43.

21. Cooper, D. P. and N. Ferguson. Traffic Studies at T-Junctions: 2. A Conflict Simulation Model. Traffic Engineering and Control, 1976, pp. 306-309.

22. Baker, W. T. An Evaluation of the Traffic Conflict Technique. Highway Research Record 384, HRB, 1972, pp. 1-8.

23. Paddock, R. D. The Traffic Conflict Technique: An Accident Prediction Method. Ohio Department of Transportation, 1974.

24. Glauz, W. D. and D. J. Migletz. Application of Traffic Conflict Anal- ysis at Intersections. NCHRP Report 219, 1980.

25. Cooper, P. J. Predicting Intersection Accidents. Canada Road and Motor Vehicle Traffic Safety Branch, Ministry of Transport, 1973.

26. Spicer, B. R. A Traffic Conflict Study at an Intersection on the Andoversford By-Pass. TRRL Report LR 520. UK Transport and Road Research Laboratory, Crowthome, Berkshire, England, 1972.

27. Asnmssen, E., ed. International Calibration of Traffic Conflict Techniques. Institute for Road Research, Netherlands, 1984.

28. Nel, P. W. Traffic Conflict Measuring Techniques: A User's Manual. Division of Road and Transport Technology, Council for Scientific and Industrial Research, Pretoria, South Africa, 1989.

29. Proceedings from the First Workshop On Traffic Conflicts. Institute of Transport Economics, Oslo, Norway, 1977.

30. Glennon, J. C., W. D. Glauz, M. C. Sharp and B. A Thorson. Critique of the Traffic-Conflict Technique. Transportation Research Record 630, 1977, pp. 32-38.

31. Glauz, W. D., K. M. Bauer and D. J. Migletz. Expected Traffic Conflict Rates and Their Use in Predicting Accidents. Transportation Research Record 1026, 1985, pp. 1-12.

32. Fazio, J., J. Holden and N. M. RouphaiI. Use of Freeway Conflict Rates as an AItemative to Crash Rates in Weaving Section Safety Analysis. Transportation Research Record 1401, 1993, pp. 61-69.

33. Gettman, D. and L. Head, Surrogate Safety Measures from Traffic Simulation Models. Report FHWA-RD-03-050. FHWA, U.S. Department of Transportation, 2003.

34. Parsonson, P. S. Signalization of High-Speed, Isolated Intersections. Transportation Research Record 681, 1978, pp. 34-42.

35. Smaglik, E., D. M. Bullock and T. Urbanik. Evaluation of Lane-byLane Vehicle Detection for Actuated Controllers Serving Multilane Approaches. Transportation Research Record, No. 1925, 2005, pp. 123133.

The contents of this paper reflect the views of the authors, who are responsible for the facts and the accuracy of the data presented, and do not necessarily reflect the official views or policies of the sponsoring organizations, nor do the contents constitute a standard, specification, or regulation.

The Traffic Signal Systems Committee sponsored publication of this paper. 